\title{
REPERCUSIONES SOCIO-ECONOMICAS DE LA GUERRA DE GRANADA EN MURCIA (1488)
}

Por

JUAN ABELLAN PEREZ 


\section{INTRODUCCION}

Frente a la unidad que constituye Castilla, el mundo musulmán hispánico, sensiblemente reducido tras las campañas de los años 1486 y 1487, dividido en dos bloques, Granada y el Norte de Almería - Vélez Blanco, Véliz Rubio y Vera - bajo la obediencia de Boabdil, vasallo de Castilla, y Guadix, Baza y Almería en poder de El Zagal, que se titula rey de la primera localidad, va a sufrir una considerable disminución territorial en su parte oriental y septentrional a consecuencia de la campaña de 1488, que como se había proyectado se inicia en la frontera oriental nazari con la presencia de los Reyes Católicos en Murcia (1), zona donde la actividad militar, de otros años, había quedado bajo la iniciativa del Adelantado Mayor del reino, reduciéndose a incursiones, razzias, cabalgadas... de escasa duración y con fines muy concretos; por tanto, el establecimiento de Murcia como centro de concentración de las huestes, va a acentuar la situación de penuria a que poco a poco va llegando la

(1) Una obra fundamental para comprender la historia murciana en época de los Reyes Católicos, es sin duda, la de Bosque CarcellzR, R.: Murcia y los Reyes Católicos. Murcia, 1953, donde se maneja y publica por primera vez una gran parte de las fuentes documentales inéditas que de los Reyes Católicos se conservan en el Archivo Municipal de Murcia, y en relación a la campaña de 1488 el capítulo IV, págs. 62-72, donde describe minuciosamente todos los preparativos sobre la llegada y estancia de los monarcas castellanos. 
población murciana, al tener que contribuir a esta conflagración políticomilitar como parte integrada en la corona castellana y acompañar a don Fernando en su entrada en tierras musulmanas (2), y después para defender los lugares anexionados contra los ataques de El Zagal, que aprovechando la partida de los reyes de las tierras murcianas y la disolución de su heterogéneo ejército, intentaba su recuperación. En consecuencia, la población de Murcia tuvo que mantener durante casi todo este año a grupos armados, con las consiguientes derramas de maravedíes para el pago de la soldada, realizar igualmente repartimientos de víveres, bestias..., para abastecer el real y para mantener las guarniciones que quedaron en los lugares que habían capitulado.

\section{APORTACION HUMANA}

El 22 de mayo de 1488 se inicia en Murcia la recluta del primer repartimiento de hombres para la prosecución de la guerra de Granada. Se trata del servicio anual por vía de Hermandad, que asciende a un total de 57 peones, distribuidos en 35 ballesteros, 12 lanceros y 10 azadoneros con palas de hierro (3), correspondiendo a cada colación de la ciudad las cifras siguientes:

\begin{tabular}{|c|c|c|c|c|}
\hline Parroguia & Ballesteros & Lanceros & Azadoneros & Total \\
\hline \multirow[t]{2}{*}{ 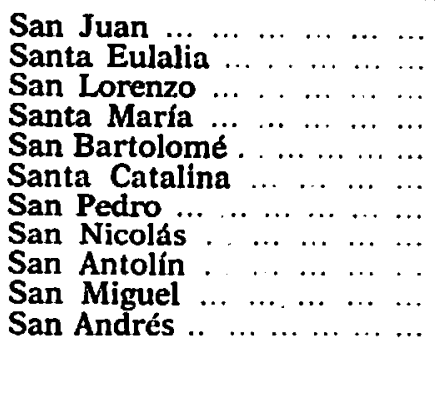 } & $\begin{array}{l}6 \\
5 \\
2 \\
3 \\
2 \\
2 \\
2 \\
2 \\
5 \\
4 \\
2\end{array}$ & $\begin{array}{l}- \\
\overline{3} \\
2 \\
2 \\
2 \\
2 \\
1 \\
=\end{array}$ & $\begin{array}{l}-1 \\
2 \\
2 \\
1 \\
1 \\
1 \\
1 \\
1 \\
-\end{array}$ & $\begin{array}{l}6 \\
6 \\
4 \\
8 \\
5 \\
5 \\
5 \\
5 \\
7 \\
4 \\
2\end{array}$ \\
\hline & 35 & 12 & 10 & 57 \\
\hline
\end{tabular}

(2) Los logros de la rápida campaña que dirige personalmente don Fernando se fundamenta en una de las razones apuntadas por Bosoue Carceller en la Op. cit., 
La normativa de este repartimiento con el lugar y fecha de presentación de todos los peones de la provincia de la hermandad murciana (4), no se conoce, aunque debió diferir muy poco o nada de los anteriores, ya que no se conserva el original ni un traslado de los que debieron enviar los reyes o el juez ejecutor de la provincia de hermandad; pese a ello, es de suponer que dada la presencia de los Reyes Católicos en Murcia y en inicio de la ofensiva castellana en la frontera oriental granadina, que la concentración militar se efectuara en Murcia.

A estos 57 peones se habrían de unir 100 lanzas a la jineta y 1.500 peones - 1.000 lanceros y 500 ballesteros - según la carta de los reyes fechada en Murcia el 3 de mayo de 1488 (5) y presentada al concejo por Pedro de Castro, contino de sus majestades, dos días después de su data. A diferencia del anterior repartimiento, este es más rápido, y en presencia del citado contino los oficiales de la asamblea local ordenaron a los jurados, en aquella misma sesión (6), que para el día siguiente, martes, presentaran ante Pedro de Castro los padrones de sus parroquias para comprobar los peones y caballeros que habian para este servicio y su puesta en nómina. De esta manera, sabida la verdad se hiciera relación cierta y detallada a sus altezas del número de individuos disponibles para la confragación bélica.

pág. 70: a... no se comprende fácilmente sin un previo entendimiento con las autoridades nıoras de la zona ocupadan, y por el profesor LADERo QUESADA en Granada. Historia de un país islámico (1232-1571), pág. 147: a... las seguridades otorgadas a aquellos musulmanes que iban a ser vasallos del señorío de Muhammad XII en el tuturon; ya que los ataques dirigidos contra las plazas que obedecian al Zagal -Almería y Baza - fueron un fracaso, y al que sin duda debió contribuir las numerosas tuarniciones que el rey habia dejado en los lugares ocupados.

(3) A.M.MU.A.C. $1487 / 88$. Sesión: sábado 22-III-1488, fols, $107 \mathrm{r}-\mathrm{v}$.

(4) En carta fechada en Zaragoza, a 26 de noviembre de 1487, los Reyes Ca. tólicos comunicaban al concejo murciano que la Junta General de la Hermandad que se había de celebrar en la villa de Aranda, a finales de 1487, se atrasaba al mes de enero de 1488, y a través de juez ejecutór de la provincia-recibirían notificación para que enviaran sus procuradores para que estuvieran en la citada villa el día 25. Apéndice documental, núm. 1.

(5) Véase Bosoue Carceller: Op. cit., Apéndice documental núm. 15, págs. 155157 y A. M. MU. A. C. $1487 / 88$. Sesión: lunes, 5-V-1488, fol. 125 v.

(6) Ut supra. 
Este mes de mayo es uno de los que registran mayor número de sesiones, ordinarias y extraordinarias, con motivo del segundo repartimiento. Las especiales circunstancias que concurren, junto a los tradicionales y continuos servicios bélicos, peste, malas cosechas... que venían empobreciendo a la población de esta ciudad, ahora se acentúan con la presencia real en Murcia y el consiguiente gasto que ello suponía; por todo ello, difícilmente se podía reclutar el número de soldados solicitado y mucho menos pagar las fabulosas cifras de dinero a que ascendía el suelo que debían percibir. De todo ello se habló en la sesión concejil del 9, en la que acordó que el corregidor y las personas diputadas por él las comunicaran al consejo real y al comendador mayor, en la espera de una reducción del número de los 100 caballeros y 1.500 peones. En principio la respuesta debió ser negativa o tal vez se dilató, pues el día 10 la asamblea dio orden para el empadronamiento de los peones, con expresa orden a los jurados para que ellos personalmente apercibieran a cada uno de los peones en presencia de un escribano para que estuvieran «prestos e aparejados» con talegas de veinte días para partir cuando fuesen llamados; sin embargo, el sábado 13, al tratar en el cabildo del sueldo que aquéllos habían de recibir, se observa ya una reducción de 500 peones y posteriormente en la sesión del día 30 se habla sólo de 900 . Si en el número de los peones hay una disminución de 600 , no ocurre los mismos con los caballeros, es más, algunos de los regidores y jurados decidieron por propia voluntad acudir a esta contienda por servir a sus altezas, siendo francos por privilegios y leyes especiales (7). Así con la solución de la problemática de los caballeros y el apercibimiento de todos - caballeros y peones- para ir a la guerra, se ordena que entre el primer día de Pascua a San Antón se hiciera el alarde, efectuándose la salida el 5 de junio (8).

(7) A. M. MU. A. C. 1487/88. Sesión: Miércoles, 14-V-1488, fol. 128 v. Como en el repartimiento de los peones el concejo dio cargo a los jurados para que supieran los caballeros que van de cada colación, si estaban aderezados y qué personas iban y de qué suerte. Sesión: martes, 13-v-1488, fol. $128 \mathrm{v}$.

(8) En la sesión: viernes 30-V-1488, fols. 132 r-v. y Bosoue Carceller: Op. cit., pág. 67, se cita a los hombres que encabezaban la milicia murciana. Como portador de la seña de la ciudad fue nombrado el regidor Rodrigo de Arróniz y como acom- 
Tras la rápida campaña efectuada por el rey don Fernando y su partida hacia Valladolid, la población murciana tuvo que realizar tres nuevos repartimientos de peones en agosto, septiembre y noviembre, a pedimento del capitán general de la frontera Luis Puertocarrero (9). EI primero comienza el 25 de agosto con la presentación en la asamblea de una carta de Puertocarrero en la que solicita en nombre de sus altezas 400 peones - reducidos posteriormente a 300- para acudir en socorro de Níjar. En aquella misma sesión, los oficiales concejiles de nuevo ordenan a los jurados el empadronamiento en sus parroquias, por ante escribano de número, siendo nombrados por la colación de:

San Juan

Santa Eulalia

San Lorenzo

Santa Maria

San Bartolomé

Santa Catalina

San Pedro

San Nicolás

San Antolín

San Miguel y

San Andrés

\author{
Rodrigo Sevillano \\ Pedro Núñez \\ Macián Conque \\ Bernaldino de Piña \\ Bartolomé Rodriguez \\ Juan Sevillano \\ Fernán Dianes \\ Pedro de Alcaraz \\ Fernando del Castillo
}

Alonso Rodríguez de Alcaraz (10)

pañantes, el bachiller Alvaro de Santisteban y Martín Riquelme, ambos del estamento de los regidores y dos de los jurados, sin especificarse el nombre.

(9) En carta dada en Murcia el 26 de julio los reyes comunicaban a... avemos acordado que Luys Puertocarrero, cuya es la villa de Palma, comendador de Azuaga e del nuestro consejo, tenga quanto nuestra merçed e voluntad fuere, cargo de nuestro capitan general en la frontera de los moros en las çibdades e villas e lugares de los obispados de Jaén e Cartajena, con el adelantamiento de Caçorla e con los lugares de la horden de Santiago que son en las syerras desde Veas hasta Murçia e con el arçedianadgo de Alcaraz... para fazer entradas a tierras de moros e guerra e mal e daño a los lugares del regno de Granada que no estan en la tregua por nos dada al rey de Granada Muley Abuabdili, nuestro vasallo...». Bosque Carceller: Op. cit., Apénd. Doc., núm. 16, pág. 159.

(10) A.M.MU. A.C. 1488/89. Sesión: lunes, 25-ViII-1488, fols. 33 r-v. 
Tres días después, en la sesión del jueves 28 , comienzan a llegar las relaciones de los individuos dispuestos para acudir al llamamiento. La primera fue la colación de San Lorenzo con un total de 12 peones, seguida de la de San Antolín con 38 (11); las restantes parroquias fueron retrasando la entrega, lo que motivó que la asamblea diera un último aviso a los jurados, presentes y ausentes, para que antes del jueves 4 de septiembre acabaran de coger los padrones (12).

En estas circunstancias llega otra carta de Luis Puertocarrero notificando el cerco puesto por los musulmanes de $E l$ Zagal a la villa de Fines y ordenando el apercibimiento de la gente de Murcia, que el concejo hizo público mediante el siguiente pregón: «Por mandado de los señores conçejo que todos cavalleros e peones desta çibdad esten prestos e aparejados con sus armas e cavallos para yr en serviçio de sus altezas quando repicare la canpana de Santa Catalina, so pena a los cavalleros de diez mill maravedis y a los peones de çinco mill maravedis para la guerra de los moros» (13). Poco después, el miércoles 17 de septiembre, Juan Fontes pregonaba el cerco puesto a Cúllar de esta manera: «Por mandado de los señores conçejo, e corregidor, e regidores que todos los cavalleros e peones veçinos e moradores de sesenta años abaxo e de diez e ocho arriba partan oy por todo el dia, los cavalleros con sus armas y cavallo y peones con sus lanças y ballestas y espingardas con la seña desta çibdat e con el señor corregidor, con provisyon de ocho dias, por quanto Luys Puertocarrero, capitan general de sus altezas en esta frontera son çertificados quel rey de Guadix esta sobre la villa de Cúllar con muchos moros y la bonbardean y conbaten, so pena de muerte, confiscaçion de todos sus bienes a cada uno que lo contrario fiziere, e que vayan todos los abonados de contia de çient mill maravedis, e que ninguno no enbie a otro por sy so la dicha pena...» (14).

(11) A. M. MU. A. C. 1488/89. Sesión: Jueves, 28-VIII-1488, fols. 35 r-36 v.

(12) Ibidem. Sesión: 1-IX-1488, fol. 41 r.

(13) Ibidem. Sesión: Miércoles 3-IX-1488, fol. $43 \mathrm{r}$.

(14) Ibidem. Sesión: Miércoles 17-IX.1488, fols. $50 \mathrm{r}$-v. En la misma sesión fue entregada la seña de la ciudad al alguacil mayor y se excusaron diversos individuos por su edad, que era superior a los 60 años, por vejez y enfermedad: Juan 
Efectivamente, la partida de las tropas se realiza el día 17, y su servicio fue de siete días, uno menos que el fijado en el pregón, así que el 23 regresaba el corregidor con la gente y la bandera de la ciudad, certificando a la asamblea que no habían ido con él más de 450 peones y 72 de caballo (15).

Desde esa fecha hasta el 20 de noviembre en que se inicia otro repartimiento, nada se sabe en Murcia de los acontecimientos bélicos en las tierras incorporadas a Castilla; sin embargo, aquel día se presentó en el concejo otra carta de los Reyes Católicos en la que ordenaban se les den 1.000 peones, cifra que se reduce a 600 , los más de ellos ballesteros y espingarderos y preparados para salir a finales de noviembre con fardeles de diez días (16). Las deliberaciones sobre el número de peones vuelven a producirse en la misma sesión, consiguiéndose otra disminución, rebajando el servicio a 400 peones, de los cuales 317 fueron lanceros, 62 ballesteros y un guía (17), y dos días después se enviaba un peón a la corte con cartas de Puertocarrero para los mensajeros de la ciudad, comunicando la aportación humana de Murcia.

La organización de la hueste continúa durante la primera mitad del mes de diciembre y siguen llegando cartas reales como la presentada por Hernando de Medina, en la que los Reyes Católicos ordenan la participación en esta contienda de todos los hijosdalgos de la ciudad (18). Por parte del concejo murciano no hubo inconvenientes para cumplir los mandatos regios, sin embargo, otros concejos como el de Lorca y Cartagena excusaron su participación a causa de la pestilencia que sufrian. Ello no fue obstáculo para que el 15 de diciembre a medio día, al toque

de Córdoba tenía un pie atronchadon, Alonso de Lorca que ano osa salir por enfermedad de vejezs, Diego Riquelme que no tiene adisposiçion de andar en guerrax, Pedro de Zambrana que estaba mal de açisyones» y no podía xarmar ni andar a cavallow...

(15) Ibidem. Sesión: martes 23-1X-1488, fol. 55 r.

(16) Ibidem. Sesión: jueves 20-XI-1488, fol. $93 \mathrm{r}$.

(17) A.M. MU. A.C. $1488 / 89$. Sesión: jueves 20XI-1488, fols. 93 v-94 r.

(18) Ibidem. Sesión: lunes 1-XII-1488, fol. $100 \mathrm{r}$. 
de las campanas de Santa Catalina, las huestes murcianas (19) salieran en socorro de la villa de Terque que estaba cercada por El Zagal, y como era costumbre fue entregada la bandera de la ciudad al alguacil mayor, Alonso de Aguilar, que entregó a su regreso, el 23-XII, al regidor, Diego de Soto.

\section{SOLDADA}

El pago de la soldada de las huestes murcianas corre a cargo de los reyes y del concejo. La cantidad que corresponde a la ciudad es una cifra que en la mayoría de los casos es superior al servicio, ello está fundamentado en el hecho de que su recaudación suele realizarse a la par que la recluta humana, y por tanto, cuando se producen reducciones en el número de peones, la mayoría de las veces no se reduce el tanto por millar establecido en las derramas que han de pagar los pecheros de la ciudad, siendo en consecuencia, más elevados los ingresos que los gastos.

Otra de las causas por las que difícilmente suelen cuadrar las cuentas, es la mezcla de conceptos, no especificándose si son por vía de hermandad o cualquier otra, agrupándolos bajo un epígrafe único, la guerra de Granada. Cuando se realiza el repartimiento del mes de mayo de 1488 se nombra al regidor, Juan de Cascales y al jurado, Juan de Córdoba para que hablasen con Hernando Alvarez, secretario de los reyes, con el ruego de que no se cobraran a la ciudad los quince mil maravedies que el licenciado Pedro Sánchez de Belmonte pedía en cumplimiento de los 160.000 maravedíes que sus altezas quisieron servirse de esta ciudad para la guerra (20), y que procuraran que los 130.000 que habían pagado se

(19) La edad fijada para este servicio afecto a todos los mayores de veintiocho años y menores de sesenta. A. M. MU. A. C. 1488/89. Sesión: 14-XII-1488, fol. 108 r.

(20) El servicio de los 160.000 maravedies para la guerra de Granada, aunque fue anulado, se ordena que la juderfa de la ciudad pagara 10.000 maravedíes e igual cantidad la morería; La Puebla. 1.200, y Fortuna, 1.000 (A.M.MU. A. C. 1487/88. Sesión: sábado 15-III-1488, fols. 103 v-104 r.). Aparte de estas cantidades, seguin dos cartas reales presentadas por Pedro de Castro en el concejo, se ordena que estas minorfas contribuyeran con el castellano de oro (A.M.MU. A. C. 1487/88. Sesión: martes 4-III-1488, fol. 98 r). 
tomaran en cuenta de los 180.000 que debian pagar a la hermandd (21). Otro punto de la citada mensajería fue el de conocer el sueldo que los reyes habrian de pagar a los caballeros peones. No tenemos noticias de los resultados obtenidos, pero sí del sueldo que el concejo hubo de pagar a sus peones, cinco maravedíes diarios durante treinta dias, lo que supone tomando los cálculos que nos ofrecen las Actas Capitulares, para 1.000 peones, 150.000 maravedíes (22). Si tenemos en cuenta que posteriormente se produce una reducción de 100 peones, queda una diferencia de 15.000 maravedíes de superávit para el concejo. La soldada de los caballeros repercute sobre los 75 abonados que no van a la guerra, con una aportación individual de 1.000 maravedíes, que hacen un total de 75.000. El salario que reciben de los reyes es de 22 maravediesdía y al que hay que sumar los 18 que les paga la ciudad hasta hacer un total de 40 maravedías diarios (23). La diferencia entre la cantidad que aportan los cuantiosos y el pago de la soldada concejil de los caballeros arroja un superávit de 21.000 maravedíes; sin embargo, estos posibles excedentes no podemos considerarlos como tales, ya que en los gastos hay que incluir a otras personas, tales como el portador de la insignia de la ciudad que percibe $200 \mathrm{mrs} /$ día, los dos regidores que la acompañan con un salario de 100 y los dos jurados que por igual motivo cobran 60 maravedíes diarios (24). Una característica de este repartimiento y, que sin duda, supuso un alivio para la población, fue la exclusión de todos los cuantiosos cuyas haciendas oscilaran entre los 50.000 y

(21) A.M.MU. A.C. 1487/88. Sesión: sábado 10-V-1488, fol. 127 v.

(22) En la sesión: martes 13-V-1488, fol. 128 r., se acuerda pagar esta cantidad de los 160.000 maravedies con que había de servir a la guerra, y de los cuales se le había hecho suelta. Esta sesión contradice la del 10, donde se dice que dicha cantidad se aplicaría a la hermandad.

(23) A. M. MU. A. C. 1487/88. Sesión: martes 13-V-1488, fols. 128 r-v.

(24) A. M. MU. A.C. 1487/88. Sesión: viernes 30-V-1488, fols. 132 r-v. 
100.000 maravedíes en el pago del salario concejil, percibiendo únicamente el de sus altezas (25).

\section{SUELDO CONCEJIL (MAYO)}

\begin{tabular}{|c|c|c|c|c|}
\hline Cuerpo & Num. Ind. & Salario/dia & Duración & Total \\
\hline \multirow[t]{2}{*}{ 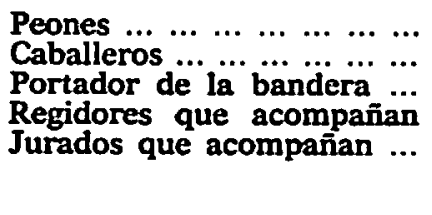 } & $\begin{array}{r}900 \\
100 \\
1 \\
2 \\
2\end{array}$ & $\begin{array}{rc}5 & \text { mrs. } \\
18 & D \\
200 & D \\
100 & D \\
60 & D\end{array}$ & $\begin{array}{l}30 \text { días } \\
30 \\
30 \\
30 \\
30\end{array}$ & $\begin{array}{r}135.000 \\
54.000 \\
6.000 \\
6.000 \\
3.600\end{array}$ \\
\hline & & & & 204.600 \\
\hline
\end{tabular}

Un aspecto a tener en cuenta al evaluar la contribución económica, es el de las deserciones, e incluso el de los individuos que movidos para asistir a la guerra no acuden, habiendo recibido su salario. A estas personas se les obliga a devolver la soldada como se contiene en el siguiente pregón: «Por mandado de los señores conçejo, corregidor, regidores desta dicha çibdad que todas e qualesquier persona, asy cavalleros como peones que resçibieron dineros de sueldo para yr a servir a sus altezas en la guerra de los moros, e no fueron ni sirvieron, e que luego lo trayan e tornen a poder de Diego de Moçon, de quien lo reçibieron, e gelo den en presençia de escrivano del conçejo, e lo ayan traydo mañana por todo el dia, so pena a cada uno que lo contrario fiziere de dos mill maravedis para la camara de sus altezas» (26).

En comparación al segundo repartimiento, el de septiembre fue menos importante desde un punto de vista económico; sólo se sabe que cada uno de los peones recibieron a su regreso de Fines 200 maravedíes por un servicio de ocho días, que ascendió a un total de 60.000 maravedíes el sueldo de los 300 peones, a razón de $25 \mathrm{mrs} /$ día (27). Posterior-

(25) Ut supra, fol. $132 \mathrm{v}$.

(26) A. M. MU. A.C. 1488/89. Sesión: martes 5-VIII-1488, fol. 22 r.

(27) Ibidem. Sesión: sábado 20-IX-1488, fol. 52 v. 
mente, sabemos que el corregidor de Murcia volvió a partir con 450 peones y 72 caballeros en socorro de la villa de Cúllar, pero no hemos encontrado ninguna noticia que haga referencia al sueldo. No ocurre lo mismo con el último repartimiento, donde se especifica con gran claridad la cantidad de maravedíes que se habrían de repartir para pagar el salario de los 400 peones - 124.000-; para su obtención se fijó una derrama de 2,5 maravedies al millar de hacienda. El sueldo se fijó en 25 maravedies, al lancero y en 30 a espingarderos y ballesteros, durante un tiempo de 10 días (28), así que, cada uno de los grupos de la milicia recibieron las cantidades siguientes:

\section{SUELDO CONCEJIL (NOVIEMBRE)}

\begin{tabular}{|c|c|c|c|c|}
\hline Cuerpo & Nüm. Ind. & Salario/dia & Duración & Total \\
\hline $\begin{array}{l}\text { PEONES: } \\
\text { Lanceros } \ldots \ldots \\
\text { Ballesteros y Espingars. } \\
\text { Guía de la tropa }\end{array}$ & $\begin{array}{r}317 \\
62 \\
!\end{array}$ & $\begin{array}{c}25 \text { mrs. } \\
30 \stackrel{\$}{300}\end{array}$ & $\begin{array}{l}10 \text { días } \\
10 \\
10\end{array}$ & $\begin{array}{r}79.250 \\
18.600 \\
3.000\end{array}$ \\
\hline
\end{tabular}

La última noticia económica de la guerra de Granada, dentro de este apartado, data del 30-XII, fecha en que el concejo ordenó a su mayodormo que pagara a Alonso de Aguilar, portador de la seña de la ciudad cuando acudieron en socorro de Terque, 200 maravedíes diarios, que hacen un total, por nueve días, de $\mathbf{1 . 8 0 0}$ maravedies.

\section{OTROS CONCEPTOS}

El envio de provisiones para la guerra, el mantenimiento y abastecimiento de las zonas conquistadas es otra de las causas que repercuten sobre la población murciana. Las noticias que a este respecto tenemos son escasas. La primera data del mes de mayo en que se comienza la

(28) Ibidem. Sesión: jueves 20-XI-1488, fols. 93 v-94 r. 
preparación de la campaña, preocupándose por el abastecimiento de las tropas, especialmente de provisiones alimenticias y para dicho fin el concejo murciano proporcionó 10.000 fanegas de cebada y 3.000 de harina, junto a otros productos que no se especifican (29). Posteriormente, el 9 de agosto, Gonzalo de Aguilar, en nombre de Fernando de Zafra (30), presentó una carta de sus altezas sobre el abastecimiento de cereales. La intervención de los jurados como intermediarios entre la asamblea y el pueblo, puso de manifiesto la existencia de 3.000 fanegas de harina, de las cuales 1.500 se dieron prestadas con condición de devolverse en el mes de junio de 1489 o su pago total o parcial en dinero a razón de $140 \mathrm{mrs} /$ arroba (31). La regulación del transporte es posterior, una semana, fijándose la cantidad de harina que cada bestia debía llevar -las mayores, tres faneras y 7,5 celemines, y las menores, 2,5 fanegasy la cuantía de maravedíes que habian de percibir cada hombre por ir, estableciéndose ésta en $10 \mathrm{mrs} /$ día por el transporte de cada fanega, ida y vuelta (32); sin embargo, el repartimiento se hizo el domingo 24:

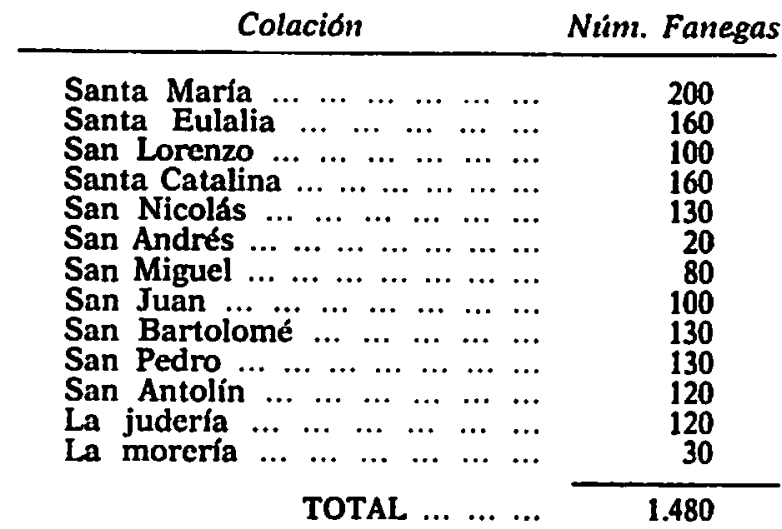

(29) Bosque Carcelier, R.: Op. cit., pág. 66.

(30) Fernando de Zafra fue encargado por los reyes, el 28-VII, del abastecimiento de los lugares ganados a los musulmanes. En el citado documento se fija el salario del transporte en 75 maravedies diarios el par de bestias mayores con su carreta y un hombre, en 50 el par de bestias menores con un hombre y en 70 el par de bestias mayores con un hombre. Bosoue CaRcelleR, R.: Op. cit., Apénd. doc. núm. 17, pág. 163. 
Después del repartimiento quedaba por resolver la forma en que se le habria de restituir las 1.480 fanegas de harina, y para ultimar esta problemática el concejo nombró a Diego Riquelme y a Juan de Cascales, para que reunidos con Fernando de Zafra le dieran una solución (33).

La misión humanitaria que realiza el concejo, en relación a la guerra de Granada, queda patente en la asamblea del 23 de agosto, donde se acordó hacer limosna de 10 reales castellanos a ciertos hombres que habian servido en la guerra y estaban en la ermita de San Antón, ya que eran pobres y no tenían para comer (34).

(31) A.M.MU. A. C. 1488/89. Sesión: sábado 9-VIII-1488, fol. 22 v.

(32) Ibidem. Sesión: sábado 16-VIII-1488, fol. $26 \mathrm{v}$.

(33) A.M.MU.A.C. 1488/89. Sesión: domingo 24-VIII-1488, fols. 32 r-v.

(34) Ibidem. Sesión: sábado 23-VIII-1488, fol. 31 v. 


\section{APENDICE DOCUMENTAL}

1487-XI-26. Zaragoza. Los Reyes Católicos comunican al concejo de Murcia que la Junta General de la Hermandad se celebraria en la villa de Aranda en el mes de enero de 1488. (A. M. MU. Cartulario $1478 / 88$, fols. 216 v. y 208 v.)

\section{El Rey e la Reyna}

Conçejo, corregidor, justiçia, regidores, caballeros, escuderos, ofiçiales e omes buenos de la çibdad de Murcia. Nuestra merçed e voluntad es que la Junta General de la Hermandad destos nuestros reynos que se avia de fazer este año del ochenta e syete se faga en el mes de henero primero que viene del año del ochenta e ocho en la villa de Aranda, porque alli les enbiaremos a mandar la gente de pie que han de aperçibir e tener presta para la guerra de los moros, que con ayuda de Nuestro Señor se ha de proseguir contra el rey e moros del reyno de Granada, sobre lo qual enbiamos a mandar al juez exsecutor de la provinçia desa çibdad que lo notifique a todas las çibdades e villas e lugares de Aranda, e que sean alli a veynte e çinco dias del dicho mes de enero del dicho año de ochenta e ocho con sus poderes bastantes para otorgar todo lo que allí les enbiaremos mandar que fagan, e para todos las cosas conplideras al nuestro serviçio e al bien de nuestros reynos e a la prosecuçion de la justiçia. 
Por ende vos mandamos que desa dicha çibdad enbies vuestros procuradores sufiçientes con vuestros poderes bastantes para todas las cosas susodichas.

De Zaragoça a veynte e seys dias de novienbre de ochenta e syete años. Yo el Rey. Yo la Reyna. Por mandado del Rey e de la Reyna, Hernand Alvares. E sobre escrito de la dicha çedula dezia: Al conçejo, justiçia, regidores, cavalleros, escuderos, ofiçiales e omes buenos de la noble çibdad de Murçia.

1488-XI-4. Valladolid. Los Reyes Católicos ordenan a la ciudad de Murcia que envien cierta gente al capitán Puertocarrero para que vayan por la mar. (A.M.MU. Cartulario 1484/95, fol. $15 \mathrm{v}$.)

\section{El Rey e la Reyna}

Conçejo, corregidor, regidores, cavalleros, escuderos, ofiçiales e omes buenos de la çibdad de Murçia. Sabed que por algunas cosas que mucho cunplen a nuestro serviçio, que nos mandamos fazer por mar a la parte de la costa dese reyno de Murçia, enbiamos mandar a Loys Portocarrero, del nuestro consejo e nuestro capitan general en esa frontera, que faga juntar alguna gente de pie, asy desa çibdad como de otras par. tes dese dicho reyno, la qual vaya en çiertas fustas por la mar con talegas por çiertos dias, e para fazer el repartimiento de la dicha gente enbiamos nuestro poder al dicho Portocarrero.

Por ende nos vos mandamos que luego que por él o por su parte fueredes requeridos le dedes e fagades dar la gente de pie que vos demandare, y le enbieys luego a enbarcar al lugar y al tienpo, y con las talegas quel dixiere, e cunplades el repartymiento que el çerca dello fiziere como sy 
nos en persona vos lo mandasemos, en lo qual nos fareys mucho plazer e serviçio.

De la villa de Valladolid a quatro días de noviembre de LXXXVIII años. Yo el Rey. Yo la Reyna. Por mandado del Rey e de la Reyna, Hernand Alvarez. En el sobrescripto dezia: Por el Rey e la Reyna al conçejo, corregidor, regidores, jurados, cavalleros, escuderos, ofiçiales e omes buenos de la çibdad de Murçia. 